\title{
Territorialidades indígenas: Paiacú e Caboré na Ribeira do Apodi $^{1}$
}

\author{
Territorialidades indígenas: Paiacú y Caboré en Ribeira del Apodi \\ Indigenous Territorialities: Paiacú and Caboré in Ribeira do Apodi
}

Ristephany Kelly da Silva Leite ${ }^{2}$

\begin{abstract}
Resumo
Nos sertões da América portuguesa, diversos eram os grupos indígenas que circulavam antes e após o contato com grupos europeus. Estes índios tinham sua própria maneira de se relacionar com o ambiente no qual estavam e, após o contato, foram forçados a ressignificar suas relações entre si e com o território devido o advento colonial. Pretende-se apresentar, neste trabalho, os grupos étnicos que habitavam a ribeira do rio Apodi, região na qual se encontrava tanto a Missão de Apodi, fundada na primeira metade do século XVIII, oriunda da tentativa de "aquietação dos povos" após intensos conflitos entre conquistadores e indígenas, que foram denominados de Guerra do Açu, quanto a Serra do Regente, local estabelecido para abrigar a vila de Portalegre, em 1761, na qual o convívio de índios e não índios era estimulado por um dispositivo legal chamado Diretório Pombalino. Trabalhando com o conceito de territórios sociais, do autor Paul Little, torna-se importante compreender como estes grupos estabeleceram suas territorialidades na ribeira do rio Apodi, como ela surgiu e em que contextos foi defendida ou reafirmada.
\end{abstract}

Palavras-Chave: Caboré; Paiacú; Sertão; Territorialidade.

\section{Resumen}

En los territorios de la América portuguesa, varios fueron los grupos indígenas que circularon antes y después del contacto con los grupos europeos. Estos indios tenían su propia manera de relacionarse con el entorno en el que se encontraban y, después del contacto, se vieron obligados a volver a significar sus relaciones entre sí y con el territorio debido a colonización. Se pretende presentar, en este trabajo, los grupos étnicos que habitaron el río Apodi, donde tanto la Misión Apodi, fundada en la primera mitad del siglo XVIII, surgió de un intento de "calmar a los pueblos" después de intensos conflictos. entre los conquistadores y los nativos, que fueron llamados la Guerra do Açu, y la Serra do Regente, un lugar establecido para albergar la vila de Portalegre en 1761, en la cual la convivencia de los indios y no indios fue estimulada por un dispositivo legal llamado el Directorio Pombalino. Al trabajar con el concepto de territorios sociales de Paul Little, es importante comprender cómo estos grupos establecieron sus territorialidades en el río Apodi, cómo surgió y en qué contextos se defendió o reafirmó.

Palabras claves: Caboré; Paiacú; Sertão; Territorialidad.

\begin{abstract}
In the sertões of Portuguese America, there were several indigenous groups that circulated before and after contact with European groups. These Indians had their own way of relating to the environment in which they were and, after contact, were forced to resignify their relations with each other and with the territory due to the
\end{abstract}

\footnotetext{
${ }^{1}$ Artigo apresentado no I Congresso Internacional Online de Estudos sobre Culturas, na modalidade online, 2019.

${ }^{2}$ Mestranda em História pelo Programa de Pós-Graduação em História e Espaços da Universidade Federal do Rio Grande do Norte (UFRN), Natal, Rio Grande do Norte, Brasil. Bolsista CAPES. Membro do Grupo de Pesquisa Formação dos Espaços Coloniais (FEC-CNPq); ristephany.kelly@gmail.com.
} 
colonial advent. The aim of this paper is to present the ethnic groups that inhabited the riverside of Apodi River, a region in which both the Apodi Mission, founded in the first half of the 18th century, originated from the attempt to "quiet the peoples" after intense conflicts. between conquerors and indigenous people, who were called the Açu War, as the Serra do Regente, a place established to house the village of Portalegre, in 1761, in which the coexistence of Indians and non-Indians was stimulated by a legal device called the Pombalino Directory. Working with the concept of social territories, by author Paul Little, it is important to understand how these groups established their territorialities on the Apodi River, how it arose and in which contexts it was defended or reaffirmed.

Keywords: Caboré; Paiacú; sertão; Territoriality.

\section{Introdução}

As denominações originadas a partir do contato entre populações originárias da América e conquistadores europeus, muitas vezes, refletem a percepção dos grupos a partir de agentes externos. Desta forma, muitas das descrições dos grupos que foram englobados na alcunha genérica de Tapuia, na realidade, partem da concepção de outros grupos rivais que também foram enquadrados em categoria genérica, os Tupi.

Os Tupi foram os grupos que viveram na faixa litorânea da América portuguesa e compartilharam o mesmo tronco linguístico, o tupi-guarani. Já os Tapuia habitavam os sertões, ocupando a região interiorana. John Monteiro escreveu excelente estudo sobre a dicotomia Tupi X Tapuia e a mudança de significados destas denominações de acordo com a escrita histórica (MONTEIRO, 2001).

Os grupos que habitavam as regiões interioranas das capitanias do Norte da América portuguesa estavam enquadrados na denominação de Tapuia para os conquistadores, mas eram bastante diversos, e tinham relações muito distintas entre si. Portanto, é preciso, ao menos, tentar compreender essas complexas relações entre estes grupos, para poder analisar como eles reagiram ao contato.

Partindo de uma visão dicotômica entre os grupos do litoral e do interior da América portuguesa, Tapuia "não se traduz como um etnônimo e sim na qualidade de uma categoria colonial, generalizante, onde estava oculta uma miríade de grupos indígenas que entraram em contato com os colonizadores" (MACEDO, 2011, p. 74), quando se intensificaram as expedições de ocupação do interior da América portuguesa.

\section{Os Grupos da Ribeira do Apodi}

Há registros de dois grandes grupos que ocuparam o interior da capitania do Rio Grande do Norte, os Cariri e os Tarairiu. Os Cariri, que habitavam as regiões limítrofes entre as capitanias do Ceará, da Paraíba e do Rio Grande, eram divididos em diversos subgrupos, com destaque para os Corema, Monxoró, Caicó e, sobretudo, Caboré e Icó Pequeno. No 
termo de ereção dos novos estabelecimentos, o juiz de fora Miguel Carlos Caldeira de Pina Castelo Branco, autoridade responsável pela ereção de parte das vilas de índios originadas das aldeias missionárias nas capitanias do Rio Grande do Norte, Paraíba e Ceará, diz ter transferido os Icozinhos para o Apodi, onde se juntaram com os Caboré e "vários casais que residiam nas serras e fazendas dos sertões do Piancó e Assú”3. As transferências decorriam de possíveis conflitos entre os grupos étnicos que iriam ocupar as missões ou vilas, como no caso dos índios Pega que foram transferidos para Mipibu, por possivelmente terem contendas com os grupos que iriam ocupar o sertão da capitania (LOPES, 2010).

O outro grande grupo que ocupava a capitania eram os Tarairiu, que também pode ser considerado uma designação genérica, por abarcar diversos grupos e ter sido utilizada durante o período de ocupação holandesa no que atualmente chamamos de nordeste brasileiro para designar os grupos do sertão. Os grupos que aparecem sendo abarcados sob esta designação, no Rio Grande do Norte, são os Ariú, Janduí, Pega, Canindé, Panati, Genipapo, Caratiú e os Paiacu. Este último grupo ocupava as capitanias do Rio Grande do Norte e do Ceará, estando uma parte deles aldeados na Missão do Apodi, em 1700 (LOPES, 2003).

As distinções entre estes grupos são expostas por Fátima Martins Lopes em sua dissertação de mestrado, primeiramente por eles ocuparem diferentes porções do território da capitania:

A primeira distinção estaria na localização das áreas culturais de influência de cada família: os Tupis habitavam o litoral; os Tarairiú, a região "sublitorânea", que se expandia além do litoral, formando uma faixa muito irregular, e, ocupando nas regiões secas do Seridó e sertão, as ribeiras dos rios Jaguaribe, Apodi, Açu, Piranhas, Sabugi e Seridó. Em alguns trechos atingia o mar, como no Ceará e Piauí. Os Cariris viviam mais para o interior dos Estados do Nordeste, nas proximidades de rios permanentes com vales úmidos, como o do Rio São Francisco (LOPES, 2003, p. 275-276).

Outras diferenças importantes de serem apontadas são os dados linguísticos, que se diferenciam entre estes grupos, sendo a língua dos Cariri bastante estudada por dois frades capuchinhos, Frei Capuchinho Luiz Vicente Mamiani e Frei Capuchinho Bernardo de Nantes. O primeiro escreveu Gramática da língua Cariri e Um catecismo da Doutrina Cristã na Língua Brasílica da Nação Cariri em 1698. Já Nantes escreveu Catecismo da Língua Cariri,

\footnotetext{
${ }^{3}$ BNRJ. Manuscritos - I-12,03,035 - Livro de registro composto, principalmente, de cartas, portarias e mapas versando sobre vários assuntos relacionados com a administração de Pernambuco e das capitanias anexas tais como: índios, estabelecimento de vilas e aldeias. Recife: [s.n.], 1760-1762. 191 f. № 258 do Catálogo dos Manuscritos sobre Pernambuco.
} 
que foi publicada em 1709. A última diferença destacada é a prática do endocanabalismo entre os chamados de Tarairiú, que os diferenciou dos demais grupos.

Entre os grupos que foram denominados genericamente de Tapuia estão os Paiacu e os Caboré, grupos que compuseram os moradores da vila de Portalegre, sendo transferidos das capitanias do Ceará e da Paraíba, além dos já habitantes da capitania do Rio Grande do Norte, enviados da Missão de Apodi e de descimentos. Apesar de haver indígenas oriundos de outros grupos étnicos na composição da vila, como os Icó e outros casais que viviam nos sertões, estes dois grupos tiveram uma representação mais expressiva na formação da vila.

A Missão do Apodi foi o primeiro grande reduto indígena no sertão da capitania do Rio Grande do Norte, acolhendo os índios que haviam se rebelado durante o período da chamada Guerra dos Bárbaros (1650-1720), uma série de conflitos que ocorreram desde o recôncavo baiano até o atual estado do Ceará, entre grupos indígenas e conquistadores que avançavam no território da América portuguesa (PUNTONI, 2002). Mais tarde, em 1761, estes grupos indígenas, junto com outros oriundos das capitanias do Ceará e da Paraíba, foram transferidos para a Serra do Regente, onde foi fundada a vila de Portalegre (LOPES, 2003). As territorialidades aqui abordadas se passam nestas duas localidades por elas já serem abrigo destas etnias antes do advento colonial, mas também por ser nelas que o contato entre índios e não índios se intensifica.

Assim, neste trabalho, pretende-se apresentar os grupos étnicos que habitavam a ribeira do rio Apodi, região na qual se encontrava tanto a Missão de Apodi, oriunda da tentativa de "aquietação dos povos" após intensos conflitos entre conquistadores e indígenas, que foram denominados de Guerra do Açu, quanto a Serra do Regente, local estabelecido para abrigar a vila de Portalegre, na qual o convívio de índios e não índios era estimulado pelo Diretório Pombalino.

Dar-se-á ênfase aos grupos étnicos que predominaram na formação da vila, notadamente os Paiacu, que já habitavam a região e haviam sido aldeados nas capitanias do Rio Grande do Norte e do Ceará. Com a transferência dos Paiacu que habitavam o Ceará, esta etnia torna-se bastante citada nos documentos. Os constantes conflitos entre os Paiacu e os moradores da capitania também são motivo para citações desse grupo, conflitos estes causados não somente por resistência dos grupos indígenas ao advento colonial, mas também pelos próprios conquistadores, até mesmo quebrando tratados de paz estabelecidos entre a Coroa e os Paiacu.

Os Paiacu se encontravam dispersos nas regiões entre as ribeiras dos rios Jaguaribe e Açu, alcançando o rio do Peixe, no atual Estado da Paraíba (VICENTE, 2011). A razão da 
ocupação de uma faixa territorial tão extensa, provavelmente reside nos deslocamentos sazonais que realizavam, ocasionados por questões climáticas e cultivo de determinados frutos, como o caju, que era utilizado em seus rituais.

Assim como ocorreu com outras populações indígenas, “diferentes grupos, em situações variadas, foram associados ao etnônimo Paiacu, geralmente localizados próximos à lagoa do Apodi ou nas ribeiras do Jaguaribe" (CRUZ, 2018, p. 65). Por vezes, os relatos sobre os grupos indígenas do período colonial são confusos, por englobar vários grupos étnicos em alcunhas genéricas, mas os registros sobre os Paiacu permitem, ainda, analisar um pouco dos costumes e práticas realizados por estes.

Alguns estudos têm sido desenvolvidos neste sentido, como o de Marcos Felipe Vicente, que, em sua dissertação de mestrado, analisou os Paiacu como principais personagens dos conflitos ocorridos na ribeira do rio Jaguaribe, no século XVII, "apresentando uma grande variedade de interesses e ações frente ao projeto colonizador" (VICENTE, 2011, p. 08). Além de fazer um levantamento sobre quais povos ocuparam a capitania do Ceará no período colonial, traduzido em mapa, o autor aponta as principais características de distinção étnica dos Paiacu, como rituais da passagem da juventude para a vida adulta e o costume das mulheres manifestarem respeito e alegria por meio de gritos e lágrimas, que afirma ser um costume comum entre os Tupi e diversos outros povos da América do sul, também encontrado entre os Paiacu.

Em Tapuias e mestiços nas aldeias e sertões do Norte, escrito por Carlos Henrique Alves Cruz, o autor faz uma análise sobre como os índios tapuias influenciam, através de suas ações e alianças, não somente reformulações interétnicas, mas também as fronteiras internas da América portuguesa, sobretudo nas ribeiras do Açu, Jaguaribe e Piancó, palco de intensos conflitos durante a Guerra do Açu (1680-1720) e de alguns dos primeiros aldeamentos nas Capitanias do Norte. Nesta obra, o autor aponta que

Desde 1671, os paiacus sofreram agressões dos colonos e seus aliados nativos, como os jaguaribara e os potiguar. Foram também contatados pelo missionário do hábito de São Pedro, João Leite de Aguiar, por volta do ano de 1691. Outras expedições militares foram realizadas contra os índios nas últimas décadas do século XVII. O mais famoso e controverso ataque ocorreu em agosto de 1699, quando sofreram "traição" comandada pelo mestre de campo Manoel Moraes Navarro, que, auxiliado por cento e trinta infantes e duzentos e cinquenta tapuias aliados, assassinou cerca de quatrocentos índios aldeados no Jaguaribe (CRUZ, 2018, p. 65).

Dedicando um capítulo para análise do episódio que ficou conhecido como massacre do Jaguaribe, o autor evidencia alianças e conflitos entre os diversos agentes sociais que 
viviam naqueles sertões, bem como reformulações de alianças, ao expor que os Paiacu se aliaram aos conquistadores portugueses e, mesmo assim, sofreram ataques, colocando em xeque inclusive a orientação régia de somente se fazer guerra justa ${ }^{4}$ contra grupos indígenas que se opusessem à colonização.

Obra escrita com propósitos distintos das citadas acima, pois pretendeu servir também como suporte didático para o Ensino de História dos grupos indígenas do interior do estado, o livro Os índios Tapuias do Rio Grande do Norte: antepassados esquecidos, traz uma breve descrição dos Paiacu. Partilhando das indicações de lugares nos quais os Paiacu habitavam, o autor acrescenta que estes

foram aldeados em diversos acampamentos, tais como Aldeia do Paiacu (AquirazCeará), Aldeia do Guajiru (estremoz-Rio Grande do Norte), Aldeia do Apodi (no córrego das missões, município de Apodí-Rio Grande do Norte) e na Missão de Nossa Senhora da Incarnação (antiga aldeia de Igramació, na ribeira do Cunhaú). A maior parte dos índios paiacu foram aldeados perto do vale do rio Jaguaribe-Ceará (Nossa Senhora da Anunciação) e na Chapada do Apodi, no Estado do Rio Grande do Norte (SANTOS JÚNIOR, 2008, p. 20-21).

Os locais apontados pelo autor como aldeamentos que receberam os índios Paiacu não estão todos contidos dentro do território que eles habitavam antes dos contatos intensos e conflitos da Guerra do Açu, o que aponta algumas das transferências realizadas, compulsórias e voluntárias, desta população.

Como apontado, a área de ocupação dos Paiacu se estendia do Açu ao Jaguaribe, sendo a ribeira do rio Apodi, o centro do trânsito deste grupo. Segue abaixo o mapa de delimitação dos principais rios onde ocorreu a ocupação territorial nas capitanias do Rio Grande do Norte e do Ceará, com destaque para as ribeiras dos rios Açu, Apodi e Jaguaribe, região na qual os Paiacu se deslocavam.

\footnotetext{
4 "A guerra justa poderia ser de caráter defensivo ou ofensivo, porém em ambos os casos deveriam obedecer às prerrogativas estabelecidas [...] para a incitação dela". Sendo essas prerrogativas: " $1^{0}$ - deve ser precedida de alguma ação injusta do inimigo; $2^{\circ}$ - deve ser impelida com intenções boas; $3^{\circ}$ - deve ser deliberada por alguma autoridade, seja a Igreja ou um príncipe". Vide: SILVA, 2019.
} 


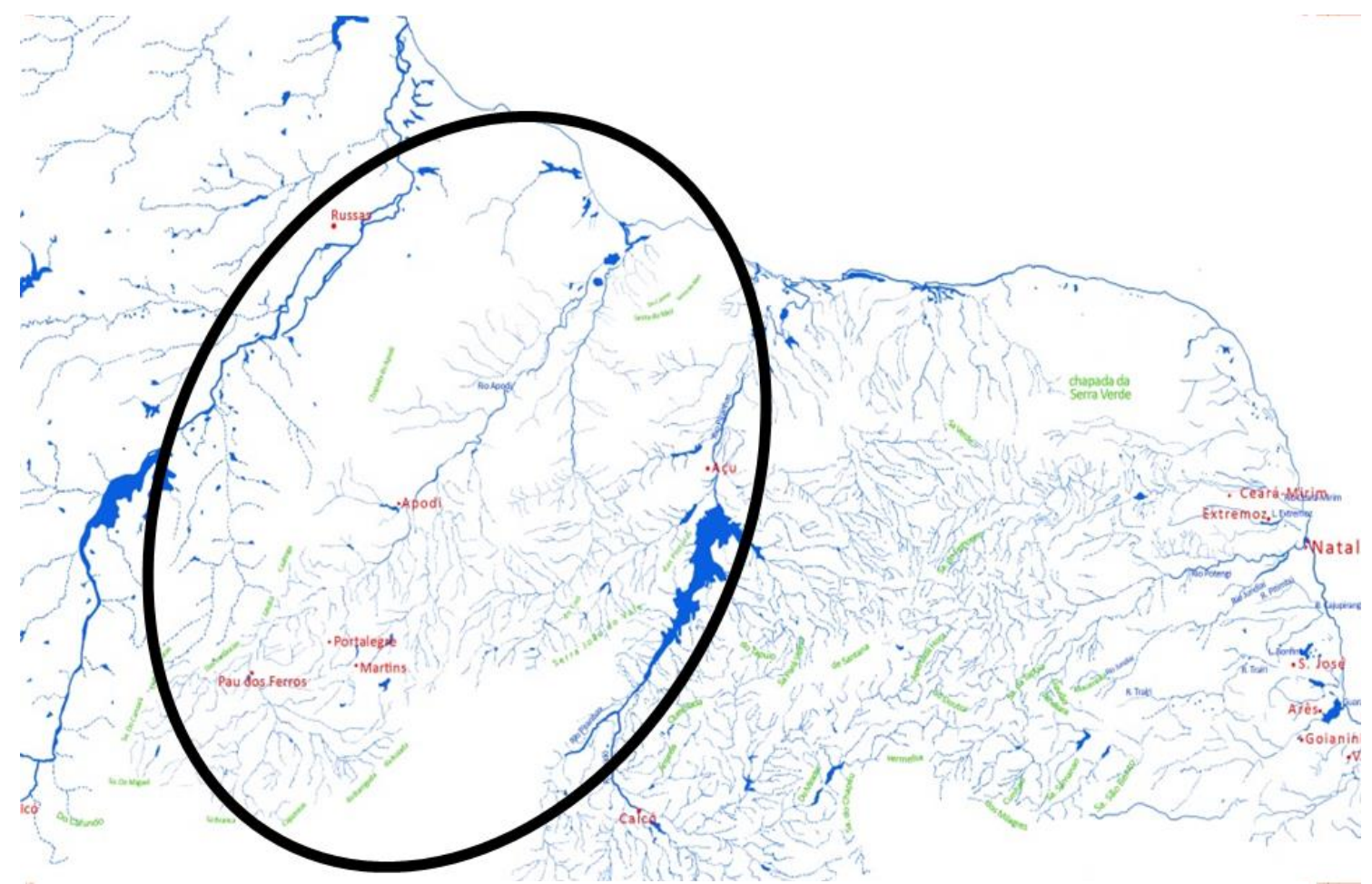

Mapa da área de ocupação dos Paiacu

Mapa elaborado por Adriel Felipe de Alcântara Silva (adriel.eu@ gmail.com)

Característica apontada nos trabalhos consultados é a resistência à expansão das fronteiras do Império ultramarino português. Valdelice Girão, professora aposentada da Universidade Federal do Ceará e autora filiada ao Instituto do Ceará, ao escrever sobre os Paiacu, apontou que "valentes, entraram em conflitos com os homens do além-mar desde as primeiras investidas portuguesas, mantendo-se também arredios ao convívio dos holandeses que aqui dominaram" (GIRÃO, 1991, p. 161). Esta passagem, quando confrontada com o que escreveu Fátima Lopes em sua dissertação de mestrado ${ }^{5}$, aponta certa discordância em relação ao convívio interétnico entre os Paiacu e os portugueses com os quais mantiveram contato, uma vez que Lopes apresentou relatos de convívio amigável entre estes. Também é questionável a afirmativa de confrontação com os holandeses, uma vez que os Paiacu poderiam se aliar a estes quando lhes fosse conveniente, permitendo conjecturar mudanças de interesse, entre estar aliado ou ser inimigo dos europeus, permitindo com que se perceba os Paiacu integrando-se no jogo colonial de interesses, formando, eles também, amizades e inimizades a partir de seus convívios e interesses.

\footnotetext{
${ }^{5}$ LOPES, Fátima Martins. Op. Cit. 2003.
} 
Estes índios foram "destacados por diversos historiadores como um dos mais hostis da região e constante infortúnio à ocupação da capitania do Ceará” (VICENTE, 2011, p. 16). No livro escrito por José Jácome Barreto e patrocinado pela Prefeitura Municipal de Portalegre, atual município do Estado do Rio Grande do Norte, o autor os aponta como um dos motivos do retardo do desenvolvimento da cidade, colocando que a presença do elemento indígena do território da cidade de Portalegre estabelecia distúrbios e provocava "dificuldades por força da própria formação hostil e do comportamento guerreiro, nômade ocioso e agressivo da raça selvícola" (BARRETO, s/d., p. 17). É preciso situar esta passagem na escrita da história dos índios no que atualmente chamamos de Nordeste brasileiro, pois se trata de uma obra escrita por um memorialista, que escreveu mais dois livros sobre municípios do Rio Grande do Norte e, portanto, não carrega uma discussão acadêmica sobre a importância destas comunidades originárias e a riqueza de suas culturas, bem como do impacto que o contato entre índios e europeus exerceu no cotidiano e na visão de mundo destes. No entanto, nos mostra a visão que os escritos anteriores às produções acadêmicas mais recentes propagavam.

O fato é que os Paiacu foram "considerados sempre muito belicosos, eram guerreiros valiosos aos lusitanos em suas campanhas de extermínio aos 'índios bravos', e a região por eles ocupada, ponto estratégico na criação e passagem das boiadas sertanejas" (CRUZ, 2018, p. 141). Apesar deste discurso ser utilizado para justificar as investidas bélicas contra os grupos indígenas, também pode ser considerado um dos motivos para as tentativas de paz e aliança com estes grupos, mesmo que depois elas viessem a ser infringidas pelos próprios agentes da Coroa na América portuguesa.

Os Caboré também são referenciados nas fontes trabalhadas nesta pesquisa, compondo outra parte do contingente populacional da vila de Portalegre. Procurar-se-á fazer uma análise sobre estes grupos, a região que habitavam e quais suas relações a partir do contato com os europeus, para procurar compreender, ao menos superficialmente, as populações que passam a compor a vila de Portalegre.

A complexidade em tratar os etnônimos indígenas torna-se ainda mais desafiante com nomes que possuem mais de uma designação. Exemplo disso é o etnônimo Caboré, que designa tanto uma etnia indígena, como poderia ser utilizado para se referir às pessoas cuja origem étnica tenha sido herdada de índios e negros. Ao desenvolver pesquisa sobre Mato Grosso no século XVIII, Maria Fátima Roberto Machado encontra documentação que distingue os índios dos Caboré, que seriam mestiços de índios com negros (MACHADO, 2006). Julie Cavignac também encontra, para o caso do Rio Grande do Norte, a associação do 
etnônimo Caboré associado a descendentes de índios com negros (CAVIGNAC, 2011, p. 195244).

No entanto, Luís da Câmara Cascudo, quando descreveu os habitantes dos sertões do Rio Grande do Norte afirmou que "o Rio Grande do Norte lembra seus ancestrais aborígenes, Paiacus, Paiins, Monsorós, Pegas, Caborés, Icózinhos, Panatis, Arius ou Áreas e Janduís, de truculenta memória, além dos Potiguares clássicos, comedores de camarão" (CASCUDO, 1984, p. 38). Apontando os Caboré como um dos grupos étnicos que habitavam o Rio Grande do Norte.

Os Caboré teriam "sido aldeados com os Paiins na zona de Mossoró e Apodi" (SANTOS JÚNIOR, 2008, p. 27) na primeira metade do século XVIII. Ocuparam outras regiões e também foram aldeados na Missão de Guajirú. Ao descrever os deslocamentos realizados para constituição das vilas de índios, o juiz de fora Pina Castelo Branco explicou que

havia mudado, por utilidade destes e pelas razões que tinha exposto em conta ao dito excelentíssimo governador, as nações Pegas e Icozinhos, aqueles para a Aldeia de Mipibu, e estes para a do Apodi, aonde tinha ajuntado, e aldeado o resto que hoje existe da Nação dos Caboré, e vários casais que residiam nas serras e fazendas dos sertões do Piancó e Assú ${ }^{6}$

Percebe-se que, para a constituição e manutenção das aldeias e, posteriormente, das vilas de índios nas Capitanias do Norte, vários foram os deslocamentos realizados. Ao que parece, no caso do Rio Grande do Norte, os agentes da Coroa na América portuguesa consideravam as inimizades entre os próprios indígenas para determinar quais grupos iriam ficar em determinada vila. Muitas vezes, era mais cômodo aldear determinados grupos em regiões mais próximas das que eles já habitavam, porém, para não haver risco de levantes e confrontos dentro das aldeias ou vila, as autoridades coloniais realizavam estes deslocamentos.

A informação de índios da etnia Caboré sendo transferidos para a Vila de Portalegre é confirmada posteriormente, pelo diretor da vila José Gonçalves da Silva quando justificava os gastos que teve ao realizar diversos deslocamentos nos sertões das Capitanias do Norte, recebendo cento e cinquenta mil reis resultantes do leilão das terras da Aldeia dos Paiacu, no Ceará, para deslocar os índios desta área para a Vila de Portalegre. O diretor alega que os cento e cinquenta mil reis "não atendia aos gastos que fazia de minha fazenda na mudança que fiz dos Caboré para a vila de Portalegre e dos Paiacu para a dita vila" ${ }^{\text {" }}$. Como se pode

\footnotetext{
${ }^{6}$ BNRJ. Manuscritos - I-12,03,035, fl. 87.

${ }^{7}$ PT-TT-CB-ER-Livro 589, fl. 54v.
} 
observar, as despesas ocasionadas por estes deslocamentos eram relativamente altas, tanto pelas longas distâncias que eram percorridas durante estes deslocamentos, quanto pela necessidade de manutenção dos povos que eram deslocados.

Assim como os Paiacu, os Caboré também entraram em conflito com os grupos invasores, sendo estes conflitos, por vezes, incitados após terem aceitado se aldear junto aos missionários. Fátima Martins Lopes apontou o caso no qual um grupo de Caboré aldeado no Açu havia sido atacado por três moços que "na ausência da maioria dos homens, matando os poucos homens que encontraram e cativando mulheres e filhos" (LOPES, 2003, p. 371), evidenciando a busca dos moradores por mão de obra escrava indígena e também propiciando retaliação por parte dos Caboré, que posteriormente mataram cinquenta e duas pessoas, gado e cavalos (LOPES, 2003).

Devemos destacar aqui novamente, que estas definições étnicas, muitas vezes, nascem no momento do contato, na necessidade de definição do que é o outro e do que esta alteridade representa. Sendo assim, aponta-se estas definições de grupos étnicos e suas principais características, mas sem perder de vista que estas identidades estavam, a todo momento, se reformulando, através de alianças estabelecidas, cisões dentro dos grupos étnicos, ou mesmo sua divisão em famílias, formando assim uma gama complexa e extensa de grupos e relações estabelecidas entre eles. Como apontou John Monteiro:

O processo inicial de invenção de um Brasil indígena envolveu a criação de um amplo repertório de nomes étnicos e de categorias sociais que buscava classificar e tornar compreensível o rico caleidoscópio de línguas e culturas antes desconhecidas pelos europeus. Mais do que isso, o quadro produzido passou a condicionar as próprias relações políticas entre europeus e nativos, não apenas na medida em que fornecia a base para a elaboração de uma legislação indigenista, mas também porque esboçava um conjunto de representações e de expectativas sobra as quais se pautavam estas relações (MONTEIRO, 2001, p. 24).

Desta forma, apesar destes etnônimos não representarem a complexidade étnica dos habitantes dos sertões da capitania do Rio Grande do Norte, é importante apontá-los para que possamos compreender quais as relações estabelecidas entre eles e, após o contato, quais as políticas adotadas pela Coroa para cada um deles, quais as alianças e acordos realizados, quais destes grupos empreenderam resistência à expansão das fronteiras e como as relações se desencadearam a partir dos conflitos ou alianças.

Trabalhando o conceito de territórios sociais, Paul Little afirmou que para analisar o território de grupos sociais "precisa-se de uma abordagem histórica que trata do contexto específico em que surgiu e dos contextos em que foi defendido e/ou reafirmado" (LITTLE, 2002, p. 3-4), por isso, torna-se importante compreender como estes grupos estabeleceram 
suas territorialidades na ribeira do rio Apodi. $\mathrm{O}$ autor também ressalta a importância de uma abordagem etnográfica, compreendendo qual a relação destes povos com o ambiente que ocupam, desta forma, a compreensão da importância das terras e dos produtos que dela advém também se torna essencial para o desenvolvimento deste trabalho.

A importância do território ocupado, por garantir a circularidade em períodos de estiagem, muito comuns naquele ambiente, fez com que os índios resistissem ao advento colonial, principalmente por elementos próprios do solo, como por exemplo o caju, serem importantes para a subsistência dos grupos, mas também para seus rituais. Desta forma, os grupos poderiam empreender resistência aos conquistadores europeus ou negociar pazes para continuar ocupando seus territórios sociais, mesmo que em conjunto com estes grupos europeus.

\section{Referências}

BARRETO, José Jacome. Portalegre, origem e contemporaneidade. Portalegre: PMP, [s.d.].

CASCUDO, Luís da Câmara. História do Rio Grande do Norte. $2^{\mathrm{a}}$ ed. Natal; Rio de Janeiro: Fundação José Augusto; Achiamé, 1984.

CAVIGNAC, Julie A. Índios, negros e Caboclos: identidades e fronteiras étnicas em perspectiva. O caso do Rio Grande do Norte. In: CARVALHO, Maria Rosário de.; CAVIGNAC, Julie A.; REESINK, Edwin (Org.). Negros no mundo dos índios: imagens, reflexos, alteridades. Natal: EDUFRN, 2011.

CRUZ, Carlos Henrique Alves. Tapuias e mestiços nas aldeias e sertões do Norte: conflitos, contatos e práticas" religiosas" nas fronteiras coloniais (1680-1761). Tese (doutorado em História), Universidade Federal Fluminense, 2018.

GIRÃO, Valdelice Carneiro. Os índios Paiacu: primeiros habitantes de Pacajus. Revista do Instituto do Ceará. Tomo CV, 1991.

LITTLE, Paul E. Territórios sociais e povos tradicionais no Brasil: por uma antropologia da territorialidade. Anuário Antropológico, Rio de Janeiro, v. 2003, p. 01-32, 2005.

LOPES, Fátima Martins. Em nome da liberdade: as vilas de índios do Rio Grande do Norte sob o diretório pombalino no século XVIII. Rio de Janeiro: PUBLIT, 2015.

LOPES, Fátima Martins. Índios, colonos e missionários na colonização da Capitania do Rio Grande do Norte. Mossoró: Fundação Vingt-Un Rosado, 2003.

MACEDO, Helder Alexandre Medeiros de. Populações indígenas no sertão do Rio Grande do Norte: História e mestiçagens. Natal: EDUFRN, 2011. 
MONTEIRO, John Manuel. Tupis, Tapuias e Historiadores: Estudos de História Indígena e do Indigenismo. Tese (Livre Docência em área de Etnologia, subárea História Indígena e do Indigenismo), IFCHUNICAMP, Campinas, 2001.

PUNTONI, Pedro. A Guerra dos Bárbaros: povos indígenas e a colonização do Nordeste do Brasil, 1650 - 1720. São Paulo: Hucitec; Editora da USP - Fapesp, 2002.

SANTOS JÚNIOR, Valdeci dos. Os índios Tapuias do Rio Grande do Norte: antepassados esquecidos. Mossoró: Fundação Vingt-un Rosado, 2008.

SILVA, Victor André Costa da. Guerras justas na capitania do Rio Grande: Guerra dos Bárbaros e desterritorialização. In: Revista Eletrônica História em Reflexão (REHR-UFGD). ISSN: 1981-2434. V. 13, nº 25. Jan./Jun. 2019.

VICENTE, Marcos Felipe. Entre São Francisco Xavier e a Madre de Deus: a etnia Paiaku nas fronteiras da colonização. Campina Grande: UFCG-Programa de Pós-Graduação em História (Dissertação de mestrado), 2011. 